\title{
Receipt of Angiotensin-Converting Enzyme Inhibitors or Angiotensin II Receptor Blockers among Medicare Beneficiaries with Diabetes and Hypertension
}

\author{
Junling Wang, Ph.D., M.S. [Associate Professor], \\ Department of Clinical Pharmacy University of Tennessee College of Pharmacy Memphis, TN \\ 38163 \\ Satya Surbhi, B.Pharm., M.S. [Graduate Research Assistant/Ph.D. Student, Health \\ Outcomes and Policy Research], and \\ Department of Clinical Pharmacy University of Tennessee College of Pharmacy Memphis, TN \\ 38163 Tel: 901-448-3521 ssurbhi@uthsc.edu
}

Julie W. Kuhle, R.Ph. [Senior Director, Performance Measurement]

Pharmacy Quality Alliance, Inc. Tel: 515-554-6685 jkuhle@pqaalliance.org

\begin{abstract}
OBJECTIVES-The proportion of patients with diabetes and hypertension receiving angiotensin-converting enzyme inhibitors or angiotensin II receptor blockers (ACE/ARB), is one of the quality measures for medication management employed by the Centers for Medicare and Medicaid Services to rate Medicare Part D plans. The objectives of this study were to determine the rate and predictors of receiving ACE/ARB in physician office and outpatient visits made by Medicare beneficiaries with diabetes and hypertension.
\end{abstract}

METHODS-The study population was Medicare beneficiaries with diabetes and hypertension from the National Ambulatory Medical Care Survey and National Hospital Ambulatory Medical Care Survey Outpatient Department, from 2007 to 2009. Predictors of receiving ACE/ARB were determined using bivariate and multivariate logistic regression analysis.

\begin{abstract}
KEY FINDINGS-Of the 6,311 Medicare outpatient and physician office visits with hypertension and diabetes, $40.70 \%$ patient visits were associated with receiving ACE/ARB. Bivariate analysis found that higher proportions of ACE/ARB were received during visits made to primary care physicians compared to visits to non-primary care physicians ( $48.39 \%$ vs. $32.56 \%$; $\mathrm{p}<0.05)$. Adjusted multivariate analyses indicated that ACE/ARB were more likely to be received during visits to primary care physicians than visits to non-primary care physicians (odds ratio [OR]: 1.96; 95\% confidence interval [CI]: 1.59-2.43), and ACE/ARB were more likely to be received during visits by patients residing in zip codes with median household income within Quartile $2(\$ 32,794-$ $\$ 40,626)$, compared to visits by patients residing in zip codes with median household income within Quartile 1 (<\$32,793, OR: 1.45; 95\% CI: 1.13-1.87).
\end{abstract}

CONCLUSIONS-Fewer than half of the patient visits were associated with receiving ACE/ ARB. Promoting evidence-based medicine and increasing access to primary care may have the potential to increase the rates of receiving ACE/ARB in this population.

Corresponding Author: Junling Wang, Ph.D., M.S. Associate Professor Department of Clinical Pharmacy University of Tennessee College of Pharmacy 881 Madison Avenue, Room 221 Memphis, TN 38163 Tel: 901-448-3601 Fax: 901-448-1221

jwang26@uthsc.edu.

DECLARATIONS

Conflict of interest: The Authors declare that they have no conflicts of interest to disclose. 


\section{Keywords}

Angiotensin-Converting Enzyme Inhibitors; Angiotensin II Receptor Blockers; Medicare; Diabetes; Hypertension

\section{INTRODUCTION}

The Medicare Prescription Drug, Improvement, and Modernization Act (MMA) implemented in 2006 introduced outpatient prescription drug (Part D) coverage for Medicare beneficiaries. Part D program was implemented to reduce out- of- pocket prescription drug expenses, lower the cost of prescription drugs, and improve access. ${ }^{[1,2]}$ In order to ensure appropriate medication management, CMS has created a quality evaluation system called the Star Ratings to indicate the quality of Medicare Part D. This rating is based on a scale of 1 to 5 stars, with 5 stars being the highest rating. One of the measures included in the Medicare Part D Star Rating is the appropriate treatment of hypertension in patients with diabetes. This is one of the six measures under the domain of Patient Safety and Accuracy of Drug Pricing. ${ }^{[3]}$ The measure indicates the percentage of patients with diabetes and hypertension who receive angiotensin-converting enzyme inhibitors or angiotensin II receptor blockers (ACE/ARB). ${ }^{[3]}$ The use of ACE/ARB has been shown to reduce cardiovascular disease (CVD) and progression of nephropathy ${ }^{[4-6]}$ and has been recommended as the first line therapy for patients with diabetes and hypertension. ${ }^{[7]}$

It has been found that the percentage of patients having diabetes and hypertension among adults 65 and older increased from $9 \%$ to $15 \%$ from 2000 to $2010 .{ }^{[8]}$ However, previous studies found low rates of utilization of ACE/ARB in patients with diabetes and hypertension. ${ }^{[9-11]}$ Because of the overall increase in medication utilization after Medicare Part D implementation, ${ }^{[12-14]}$ it is important to determine the status of the receipt of ACE/ ARB among Medicare beneficiaries with diabetes and hypertension after Part D implementation. The specific objectives of this study were (1) to determine the rate of receiving ACE/ARB in the physician office and outpatient visits by Medicare beneficiaries with diabetes and hypertension; and (2) to identify the patient and community level characteristics that predict the receipt of ACE/ARB.

\section{METHODS}

\section{Data Source}

This is a retrospective cross-sectional analysis of Medicare beneficiaries with diabetes and hypertension in the secondary databases, National Ambulatory Medical Care Survey (NAMCS) and National Hospital Ambulatory Medical Care Survey Out Patient Department (NHAMCS-OPD), from 2007 to 2009. NAMCS is a national probability sample survey conducted by the Division of Health Care Statistics, National Center for Health Statistics (NCHS). NAMCS contains a sample of visits to non-federal employed office-based physicians who are primarily engaged in direct patient care. ${ }^{[15]}$ It utilizes a multistage probability design that involves probability samples of primary sampling units (PSUs), physicians within PSUs, and patient visits within practices. PSUs are geographic segments composed of counties, groups of counties, county equivalents (such as parishes or independent cities) or towns and townships within the 50 states of United States and the District of Columbia. ${ }^{[15]}$

NHAMCS is conducted by the Ambulatory and Hospital Care Statistics Branch of the NCHS. The survey collects data from a sample of patient records selected from the emergency departments (EDs) and outpatient departments (OPDs) of a national sample of 
hospitals. NHAMCS uses a four-stage probability design with samples of geographically defined areas, hospitals within these areas, clinics/emergency service areas within outpatient/emergency departments, and patient visits within clinics/emergency service areas. This study has utilized the OPD component of the NHAMCS. ${ }^{[15]}$

The basic sampling unit for NAMCS and NHAMCS is the physician-patient encounter or visit, which is defined as a direct, personal exchange between a patient and a physician, or a staff member acting under a physician's direction, for the purpose of seeking care and rendering health services. Each physician is randomly assigned to a one week reporting period. During this period, data are collected from the physicians or office staffs who record the data of the random sample of visits on the patient record form. Data are obtained on patients' demographics, insurance status and clinical information such as physicians' diagnosis and medications ordered or provided. ${ }^{[15]}$ The most recent complete data were from the year 2009 at the time this study was conducted. The physician office visits data (NAMCS) from 2007-2009 and the outpatient department visits data (NHAMCS-OPD) from 2007-2009 were combined together in order to represent all U.S office-based and outpatient visits. The data can be combined from these two settings because they both belong to the Ambulatory Health Care Survey and they represent two different practice settings. ${ }^{[15]}$

\section{Study Sample}

The final sample consisted of visits by Medicare beneficiaries with diabetes and hypertension. Patient visits were included in the analysis if the expected source of payment was Medicare for a given visit. Furthermore, visits with diabetes and hypertension were selected based on the physician diagnosis codes (ICD-9-CM codes 401.XX-405.XX for hypertension and 250.XX for diabetes) in the database or a check mark on a list of 14 chronic conditions. NAMCS and NHAMCS provided up to 3 physicians diagnoses. Both databases also included a list of 14 chronic conditions a patient may have including hypertension and diabetes, starting from 2006. Patient visits with the following contraindications for ACE/ARB were excluded from the analyses: angioedema (ICD-9-CM 277.6, 995.1), aortic stenosis (ICD-9-CM 093.22, 395.0, 395.3, 396.2, 396.8, 424.1, 746.3), hypertrophic cardiomyopathy (ICD-9-CM 425.4, 746.84), and hyperkalemia (ICD-9-CM 276.7). ${ }^{[10]}$ As a result 89 patient visit records were excluded from the sample.

\section{Outcome Variable}

The databases used in this study include medications that were ordered, supplied, administered or continued during a visit. Therefore, the outcome variable of interest was receiving ACE/ARB defined as a record of these medications being ordered, supplied, administered or continued during a visit. This definition helped us to capture not only the $\mathrm{ACE} / \mathrm{ARB}$ received during the first visit but also if these medications were continued in subsequent visits. In this study, ACE/ARB were determined by using the Multum Lexicon therapeutic classification system included in the databases. Additionally, the medication combinations of ACE inhibitors (ACE inhibitors with calcium channel blockers, ACE inhibitors with diuretics) and the medication combinations of ARBs (ARBs with diuretics) were selected based on the recommendations in the Seventh Report of the Joint National Committee on Prevention, Detection, Evaluation, and Treatment of High Blood Pressure (JNC7). ${ }^{[16]}$ Under the Multum classification system, each combination was assigned a single generic code. Ten combinations for ACE inhibitors and seven combinations for ARBs were included in this study, which were then identified using their respective generic codes.

\section{Predictor Variables}

The present study used Andersen's Behavioral Model of Health Services Utilization. This model defines the utilization of health services as a function of (1) predisposing, (2) 
enabling, and (3) need factors. Predisposing factors refer to the individual's characteristics that are present before the illness, including demographic characteristics, social structure characteristics, and health beliefs. Enabling characteristics refer to community and personal resources and need characteristics refer to a patient's need to seek health care services. ${ }^{[17]}$ Predisposing characteristics included in this study were age, sex and race/ethnicity. Race/ ethnicity was recoded into a new variable consisting of categories including non-Hispanic Whites (Whites), non-Hispanic Blacks (Blacks), Hispanics and others. The enabling characteristics included in this study were private insurance, Medicaid, education, income, region, Metropolitan Statistical Area (MSA), and whether the provider is a primary care physician. Education was defined as the percentage of the population with bachelor's degree or higher in a patient's zip code which was categorized as Quartile 1 (Less than 12.84\%), Quartile 2 (12.84-19.66\%), Quartile 3 (19.67-31.68\%) and Quartile 4 (31.69\% or more). Income was defined as median household income in a patient's zip code which was categorized as Quartile 1 ( $\$ 32,793$ or less), Quartile 2 (\$32,794- $\$ 40,626)$, Quartile 3 $(\$ 40,627-\$ 52,387)$ and Quartile 4 (\$52,388 or more). The need characteristic included in this study was patient's total number of chronic conditions which was a count variable ranging from 0 to 14 . These 14 chronic conditions included arthritis, asthma, cancer, cerebrovascular disease, chronic renal failure, congestive heart failure, chronic obstructive pulmonary disease, depression, diabetes, hyperlipidemia, hypertension, ischemic heart disease, obesity and osteoporosis. They were determined based on the list of 14 chronic conditions in the databases.

\section{Data Analyses}

The physician office visits data from 2007-2009 and the outpatient department visits data from 2007-2009 were combined together. Bivariate and multivariate analyses were conducted to determine the factors associated with receiving ACE/ARB. For bivariate analyses, survey-weighted Wald chi-square tests were conducted to determine the statistical differences in the likelihood of receiving ACE/ARB by the predisposing, enabling and need factors. For the multivariate analyses, survey-weighted logistic regression analyses were conducted.

The complex survey design of NAMCS and NHAMCS survey were accounted for in all analyses. Observations with any missing values for the study variables were excluded from the analyses. The data analyses of this study were conducted using SAS 9.3 (SAS Institute Inc, Cary, North Carolina). The statistical significance level was set a priori at 0.05 .

\section{RESULTS}

\section{Patient Visit Characteristics}

Between the years 2007 to 2009, the total numbers of visits were 6,311 among Medicare beneficiaries with diabetes and hypertension. Characteristics of Medicare beneficiaries with diabetes and hypertension who made visits to the physician office and outpatient department were analyzed (Table 1). Higher proportions of these patient visits were made by Medicare beneficiaries in the age group 65 to 74 years $(42.19 \%)$ compared to the age groups younger than 65 years (16.86\%), 75 to 84 years (32.22\%), and 85 years and above (8.73\%). Females accounted for higher proportion of visits than males $(54.36 \%$ vs. $45.64 \%)$. Whites accounted for higher proportion of visits (71.27\%) than Blacks (15.76\%), Hispanics (9.80\%), and others (3.17\%). Majority of the Medicare beneficiaries who made visits to the physician office and outpatient department did not have a private insurance $(60.80 \%)$ or Medicaid $(88.93 \%)$. Higher proportions of visits were made by patients who resided within the zip codes with lowest education level Quartile 1 (29.49\%) compared to visits made by patients who resided within Quartile 2 (27.15\%), Quartile 3 (23.84\%), and Quartile 4 (19.52\%) of 
the education level. Similarly, higher proportions of the visits were made by patients who resided within zip codes of median household income within Quartile $1(28.69 \%)$ in comparison to zip codes of median household income within Quartile 2 (26.36\%), Quartile 3 $(24.80 \%)$, and Quartile $4(20.15 \%)$ of the income level. Higher proportions of patient visits were made to the physician practices located in the south (42.53\%) compared to midwest $(22.24 \%)$, northeast $(19.75 \%)$, and west $(15.48 \%)$ regions. Majority of the patient visits were made to the physician practices located in MSA (83.19\%). Higher proportions of visits were made to primary care physicians $(53.31 \%)$ than non-primary care physicians $(46.69 \%)$. Regarding health status, higher proportions of visits were made by patients who had 3 chronic conditions (32.00\%) compared to visits made by patients with 2 chronic conditions (17.97\%), 4 chronic conditions (25.10\%), and 5 or more chronic conditions $(24.93 \%)$.

Of the 6,311 Medicare outpatient and physician office visits made by patients with hypertension and diabetes, $40.70 \%$ patient visits were associated with receiving ACE/ARB. The association of patient and community level characteristics with the receipt of ACE/ARB was analyzed (Table 2). It was found that ACE/ARB were more likely to be received during visits to primary care physicians than visits to non-primary care physicians $(48.39 \%$ vs. $32.56 \% ; p<0.05)$. Apart from the variable for primary care physician, none of the patient and community level characteristics were significantly associated with receiving ACE/ARB. Multivariate logistic regression analysis was conducted to identify the patient and community level characteristics that predicted the receipt of ACE/ARB (Table 3). It was found that $\mathrm{ACE} / \mathrm{ARB}$ were $45 \%$ more likely to be received during visits made by patients residing in zip codes with median household income within Quartile 2 as compared to visits made by patients residing in zip codes with median household income within Quartile 1 (odds ratio [OR]: $1.45,95 \%$ confidence interval [CI]: 1.13-1.87). Visits to primary care physicians had $96 \%$ higher likelihood of receiving ACE/ARB when compared to visits to non-primary care physicians (OR: 1.96; 95\% CI: 1.59-2.43). None of the other factors were found to be significantly associated with receiving ACE/ARB.

\section{DISCUSSION}

Analysis of national survey data revealed that fewer than half of the outpatient visits were associated with receiving ACE/ARB. The lower receipt of ACE/ARB during visits in the Medicare population is a major concern, since ACE/ARB is considered the first line therapy and is one of the CMS's quality measures for medication management to rate Medicare Part D plans. ${ }^{[3,7]}$ A recent report from CMS showed the rate of utilization of ACE/ARB to be between 56.5\% and 91.9\% in the year 2011 for Medicare Advantage Prescription Drug Plans (MAPDs) and Prescription Drug Plans (PDPs). ${ }^{[18]}$ CMS annually raises the required threshold for the plans to achieve higher ratings for this measure with the objective of continuous quality improvement. For the year 2011, the 4-star threshold for the rate of ACE/ ARB use for MAPDs was $\geq 86 \%$ and for PDPs was $\geq 83 \%$; The proposed 4-star threshold for 2012 data for MA-PDs is $>87 \%$; for PDPs $>84 \% .{ }^{[18]}$

The lower rates of receiving ACE/ARB in the present study in comparison to the rates reported by the CMS may partly be explained by different methods of calculating these rates. CMS defines appropriate treatment of hypertension in patients with diabetes as the proportion of patients who received an ACE/ARB among patients who filled a medication for diabetes and hypertension. ${ }^{[3]}$ However, the sample in this study was selected based on a diagnosis for diabetes and hypertension and did not limit to individuals with a medication filled for diabetes and hypertension. Previous population-based studies found the use of ACE/ARB among patients with diabetes and hypertension to be between $46 \%$ and $64 \% .{ }^{[9-11,19]}$ Although studies conducted after implementation of Medicare part D have shown an overall increase in the medication use, ${ }^{[12-14]}$ the present study found that ACE/ 
ARB was not received during majority of the physician office and outpatient department visits made by Medicare beneficiaries with diabetes and hypertension.

The lower rates of receiving these medications might also be due to physicians failing to prescribe ACE/ARB. The 2010 Patient Protection and Affordable Care Act (ACA) has directed efforts at physicians to promote the practice of evidence based medicine. One ACA provision is to allow providers organized as Accountable Care Organizations (ACOs) that voluntarily meet quality thresholds, to share in the cost savings they achieve for the Medicare program. To qualify as an ACO, organizations must agree to be accountable for the overall care of their Medicare beneficiaries, have adequate participation of primary care physicians, define processes to promote evidence-based medicine, report on quality and costs, and coordinate care. ${ }^{[20]}$ This provision may increase the receipt of ACE/ARB among patients with diabetes and hypertension.

Another approach to achieve high plan rating for the measure of receiving ACE/ARB among Medicare beneficiaries with diabetes and hypertension would be to provide MTM services by pharmacists and other qualified health care providers. ${ }^{[21]}$ Being one of the most accessible health care professionals, pharmacists are in a prime position to provide these services. ${ }^{[22]}$ Studies have reported the benefit of incorporating pharmacists as a part of the health care team for managing chronic diseases. ${ }^{[23,24]}$ One study reported $41.41 \%$ prescriber approval rate for guideline-adherent recommendations by the pharmacists. ${ }^{[25]}$ The same study also found that primary care physicians had higher approval rates of pharmacists' recommendation than specialists. ${ }^{[25]}$ Since primary care physicians are in short supply, pharmacists may take more active role in the health care team. The National Quality Strategy, which is required by the ACA, addresses a range of quality concerns affecting individuals. ${ }^{[26]}$ Although there are many accepted quality measures, it has been found that inadequate measures exist in some areas, such as care coordination and patient engagement. ${ }^{[26]}$ Providing MTM services can be one of the ways to address issues with care coordination and patient engagement.

The bivariate and multivariate findings revealed that patients who made visits to primary care physicians were more likely to receive ACE/ARB. This finding is consistent with other studies which have found positive patient outcomes associated with having access to a primary care physician. ${ }^{[27,28]}$ The United States healthcare system has been facing a decline in its primary care workforce. Lack of financial incentives and poor reimbursement have resulted in many physicians choosing to train and practice specialty medicine. ${ }^{[29]}$ Studies have found that although 56\% of patient visits in America are primary care, only 37\% of physicians practice primary care medicine, and only $8 \%$ of the nation's medical school graduates go into family medicine. ${ }^{[30,31]} \mathrm{ACA}$ also has several provisions aimed at improving access to primary care which includes a $10 \%$ bonus for primary care providers under the Medicare fee schedule and an additional \$230 million in award grants which will go to teaching health centers to start primary care residency programs. ${ }^{[20]}$ One challenge in the successful implementation of these provisions would be the long time period required to train new primary care physicians.

This study found that visits made by patients from the zip codes with median household income within Quartile 2 were more likely to be associated with receiving ACE/ARB compared to visits made by patients from the zip codes with median household income within Quartile 1. None of the other patient and community level factors were associated with receiving ACE/ARB. In contrast, other population-based studies found the use of ACE/ ARB to be associated with socio-demographic factors. These factors included gender, age and race in previous studies. ${ }^{[9-11,19]}$ Since this study was based on a sample of physician office and outpatient visits, the patients already had access to health care. Additionally, 
unlike other population based studies, the enabling characteristics such as education and income denote the education and income level of an area rather than the individual. These might be some reasons for the lack of significant association between socio-demographic characteristics and receiving ACE/ARB.

The present study has made new contributions to the existing research. First, the study updates previous research on the rate of ACE/ARB among Medicare beneficiaries by using data after the implementation of Medicare Part D. Second, in this study the data is collected from the patient record form filled up by the providers, and are not based on recall by patients, which may provide a better assessment of the quality of care provided during routine visits to the physician office and outpatient department settings. ${ }^{[15]}$ Thus, findings from this study provide updated information to policy makers, health plans, and physicians regarding the adequacy of the evidence-based pharmacotherapy in patients with diabetes and hypertension. In addition, this study also highlights the positive association between visits made to primary care physicians and receiving the recommended pharmacotherapy for the treatment of hypertension among diabetic patients. The findings of this study add to the body of evidence, indicating the importance of primary care physicians and may provide policy makers further justification to increase the supply of these providers.

Our study has some limitations. First, the data does not contain patient identifier so it cannot be used to determine prevalence estimates. Since the data is based on visits, it is possible that sicker patients and those making more frequent follow-up visits may be repeated in the sample. Second, this study used the NAMCS and NHAMCS OPD databases (2007 to 2009) which are secondary in nature. As a result, this study had to rely on only those variables which are available in the databases. Third, the results of this study are only applicable to patients making physician-office and outpatient visits and do not represent the entire U.S. population. Fourth, the databases include only 8 prescribed medications, thus it is possible that ACE/ARB could have been omitted for patients treated with more than 8 drugs. Finally, NAMCS and NHAMCS databases do not report income at the individual level while income at the individual level can be a more reliable measure compared to the income level according to the zip codes.

\section{CONCLUSION}

Fewer than half of the outpatient visits by Medicare beneficiaries with diabetes and hypertension were associated with receiving ACE/ARB. Promoting evidence-based medicine, increasing access to primary care physicians, and increasing the role of pharmacists in patient care may have the potential to increase the rate of receiving ACE/ ARB in visits made by this population. Future studies should also consider other physician related factors which might contribute to better understanding of the barriers to patients receiving ACE/ARB among Medicare beneficiaries with diabetes and hypertension.

\section{Acknowledgments}

Funding: The project described was supported by Grant Number R01AG040146 from the National Institute On Aging. The content is solely the responsibility of the authors and does not necessarily represent the official views of the National Institute On Aging or the National Institutes of Health.

\section{REFERENCES}

1. Centers for Medicare \& Medicaid Services. Department of Health \& Human Services. Medicare Program; Medicare prescription drug benefit: final rule. Fed Regist. 2005; 70:4193-4585. [PubMed: 15678603] 
2. Wang J, et al. Disparity implications of Medicare eligibility criteria for medication therapy management services. Health Serv Res. 2010; 45:1061-1082. [PubMed: 20500223]

3. Pharmacy Quality Alliance, Inc.. [June 9, 2013] Executive update on medication quality measures in Medicare Part D plan ratings. 2013. http://pqaalliance.org/measures/cms.asp

4. Abuissa $\mathrm{H}$, et al. Angiotensin-converting enzyme inhibitors or angiotensin receptor blockers for prevention of type 2 diabetes: a meta-analysis of randomized clinical trials. J Am Coll Cardiol. 2005; 46(5):821-826. [PubMed: 16139131]

5. Brenner BM, et al. Effects of losartan on renal and cardiovascular outcomes in patients with type 2 diabetes and nephropathy. N Engl J Med. 2001; 345(12):861-869. [PubMed: 11565518]

6. Chaturvedi N. HOPE and extension of the indications for ACE inhibitors? Heart Outcomes Prevention Evaluation. Lancet. 2000; 355(9200):246-247. [PubMed: 10675066]

7. Standards of medical care in diabetes - 2011. Diabetes Care. 2011; 34(Suppl 1):S11-S61. [PubMed: 21193625]

8. Freid VM, et al. Multiple chronic conditions among adults aged 45 and over: trends over the past 10 years. NCHS Data Brief. 2012; 100:1-8. [PubMed: 23101759]

9. Rosen $\mathrm{AB}$, et al. Use of angiotensin-converting enzyme inhibitors and angiotensin receptor blockers in high-risk clinical and ethnic groups with diabetes. J Gen Intern Med. 2004; 19(6):669-75. [PubMed: 15209606]

10. Aparasu RR, Aparasu A. Hypertension management in outpatient visits by diabetic patients. Res Social Adm Pharm. 2008; 4(3):284-291. [PubMed: 18794038]

11. Johnson ML, Singh H. Patterns of antihypertensive therapy among patients with diabetes. J Gen Intern Med. 2005; 20(9):842-846. [PubMed: 16117753]

12. Lichtenberg FR, Sun SX. The impact of Medicare Part D on prescription drug use by the elderly. Health Aff (Millwood). 2007; 26(6):1735-1744. [PubMed: 17978393]

13. Yin W, et al. The effect of the Medicare Part D prescription benefit on drug utilization and expenditures. Ann Intern Med. 2008; 148(3):169-177. [PubMed: 18180465]

14. Ketcham JD, Simon KI. Medicare Part D's effects on elderly patients' drug costs and utilization. Am J Manag Care. 2008; 14(11 Suppl):SP14-SP22. [PubMed: 18991476]

15. [January 3 2013] Ambulatory Health Care Data. Centers for Disease Control and Prevention. 2012. http://www.cdc.gov/nchs/ahcd.htm

16. [February 26 2013] The Seventh Report of the Joint National Committee on Prevention, Detection, Evaluation, and Treatment of High Blood Pressure. 2004. http://www.nhlbi.nih.gov/guidelines/ hypertension/jnc7full.pdf

17. Andersen RM. Revisiting the behavioral model and access to medical care: does it matter? J Health Soc Behav. 1995; 36(1):1-10. [PubMed: 7738325]

18. Part C and D performance data. Centers for Medicare and Medicaid Services; http://www.cms.gov/ Medicare/Prescription-Drug-Coverage/PrescriptionDrugCovGenIn/PerformanceData.html [May 7 2013]

19. Winkelmayer WC, et al. Underuse of ACE inhibitors and angiotensin II receptor blockers in elderly patients with diabetes. Am J Kidney Dis. 2005; 46(6):1080-1087. [PubMed: 16310574]

20. Summary of New Health Reform Law. Focus on Health Reform. The Henry J. Kaiser Family Foundation.; 2011. http://www.kff.org/healthreform/upload/8061.pdf [January 3 2013]

21. American Pharmacists Association and National Association of Chain Drug Stores Foundation. Medication therapy management in community pharmacy practice: core elements of an MTM Service (Version 1.0). J Am Pharm Assoc. 2005; 45(5):573-579.

22. Steeb D, Webster L. Improving care transitions: optimizing medication reconciliation. J Am Pharm Assoc. 2003; 52(4):e43-52.

23. Smith M. Pharmacists' role in improving diabetes medication management. J Diabetes Sci Technol. 2009; 3(1):175-9. [PubMed: 20046662]

24. Hunt JS, et al. A randomized controlled trial of team-based care: impact of physician-pharmacist collaboration on uncontrolled hypertension. J Gen Intern Med. 2008; 23(12):1966-72. [PubMed: 18815843] 
25. Perera PN, et al. Evaluation of prescriber responses to pharmacist recommendations communicated by fax in a medication therapy management program (MTMP). J Manag Care Pharm. 2011; 17(5): 345-354. [PubMed: 21657804]

26. Conway $\mathrm{PH}$, et al. The future of quality measurement for improvement and accountability. JAMA. 2013; 309(21):2215-2216. [PubMed: 23736730]

27. Fang J, et al. Hypertension control at physicians' offices in the United States. Am J Hypertens. 2008; 21(2):136-142. [PubMed: 18188159]

28. Starfield B, et al. Contribution of primary care to health systems and health. Milbank Q. 2005; 83(3):457-502. [PubMed: 16202000]

29. [January 4, 2013] Primary Care Shortage. 2011. http://www.kaiseredu.org/Issue-Modules/PrimaryCare-Shortage/Background-Brief.aspx\#footnote4

30. Halsey, A. [January 5 2013] Primary Care Shortage May Undermine Reform Efforts. 2009. http:// www.washingtonpost.com/wpdyn/content/article/2009/06/19/AR2009061903583.html

31. Bureau of Health Professions. The physician work-force. Health Resources and Services Administration; 2008. http://bhpr.hrsa.gov/healthworkforce/reports/physwfissues.pdf [January 5 2013] 
Table 1

Characteristics of Medicare beneficiaries with diabetes and hypertension who made visits to the physician office and outpatient department from 2007-2009

\begin{tabular}{|c|c|c|c|c|}
\hline \multirow[t]{2}{*}{ Characteristics } & \multirow[t]{2}{*}{ Groups } & \multicolumn{2}{|c|}{ Number of Visits } & \multirow{2}{*}{$\begin{array}{r}\text { Frequency }^{a} \\
\%\end{array}$} \\
\hline & & Unweighted & Weighted & \\
\hline \multirow[t]{4}{*}{ Age } & $<65$ & 1,534 & $19,479,744$ & 16.86 \\
\hline & $65-74$ & 2,512 & $48,749,226$ & 42.19 \\
\hline & $75-84$ & 1,796 & $37,235,518$ & 32.22 \\
\hline & $85 \&$ above & 469 & $10,091,732$ & 8.73 \\
\hline \multirow[t]{2}{*}{ Sex } & Female & 3,453 & $62,822,050$ & 54.36 \\
\hline & Male & 2,858 & $52,734,170$ & 45.64 \\
\hline \multirow[t]{4}{*}{ Race/Ethnicity } & Non-Hispanic White & 4,124 & $81,916,015$ & 70.89 \\
\hline & Non-Hispanic Black & 1,243 & $18,100,158$ & 15.66 \\
\hline & Hispanic & 631 & $11,526,445$ & 9.98 \\
\hline & Other & 313 & $4,013,602$ & 3.47 \\
\hline \multirow[t]{2}{*}{ Private Insurance } & No & 4,290 & $70,263,906$ & 60.80 \\
\hline & Yes & 2,021 & $45,292,314$ & 39.20 \\
\hline \multirow[t]{2}{*}{ Medicaid } & No & 5,283 & $102,766,767$ & 88.93 \\
\hline & Yes & 1,028 & $12,789,453$ & 11.07 \\
\hline \multirow[t]{2}{*}{ Bachelor's Degree or Higher in Patient's } & Quartile 1 & 1,860 & $32,908,309$ & 29.49 \\
\hline & Quartile 2 & 1,577 & $30,301,129$ & 27.15 \\
\hline \multirow[t]{2}{*}{ ZIP code ${ }^{b}$} & Quartile 3 & 1,482 & $26,603,958$ & 23.84 \\
\hline & Quartile 4 & 1,155 & $21,775,147$ & 19.52 \\
\hline Median Household & Quartile 1 & 2,025 & $32,017,111$ & 28.69 \\
\hline Income in Patient's & Quartile 2 & 1,572 & $29,412,070$ & 26.36 \\
\hline \multirow[t]{2}{*}{ ZIP code ${ }^{c}$} & Quartile 3 & 1,346 & $27,675,214$ & 24.80 \\
\hline & Quartile 4 & 1,131 & $22,484,148$ & 20.15 \\
\hline \multirow[t]{4}{*}{ Region } & Northeast & 1,674 & $22,822,815$ & 19.75 \\
\hline & Midwest & 1,494 & $25,704,882$ & 22.24 \\
\hline & South & 2,217 & $49,142,118$ & 42.53 \\
\hline & West & 926 & $17,886,405$ & 15.48 \\
\hline \multirow[t]{2}{*}{ MSA } & Non-MSA & 901 & $19,430,699$ & 16.81 \\
\hline & MSA & 5,410 & $96,125,521$ & 83.19 \\
\hline Primary Care & No & 3,920 & $51,810,867$ & 46.69 \\
\hline Physician Visit ${ }^{d}$ & Yes & 2,154 & $59,159,879$ & 53.31 \\
\hline \multirow[t]{4}{*}{ Number of Chronic Conditions } & 2 & 1,188 & $20,762,948$ & 17.97 \\
\hline & 3 & 1,949 & $36,965,438$ & 31.99 \\
\hline & 4 & 1,617 & $28,989,556$ & 25.09 \\
\hline & 5 or more & 1,557 & $28,796,684$ & 24.95 \\
\hline
\end{tabular}

$a_{\text {Percentage of visits }}$ 
${ }^{b}$ Information on 237 visits were missing for the variable, 'Bachelor's degree or higher in patient's zip code.'

${ }^{c}$ Information on 237 visits were missing for the variable, 'Median household income in patient's zip code.'

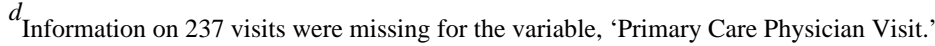


Table 2

Bivariate association of patient characteristics with receipt of ACE/ARB among visits by Medicare beneficiaries with diabetes and hypertension from 2007-2009

\begin{tabular}{|c|c|c|c|c|c|}
\hline \multirow[t]{2}{*}{ Characteristics } & \multirow[t]{2}{*}{ Groups } & \multicolumn{2}{|c|}{ Visits Receiving ACE/ARB } & \multicolumn{2}{|c|}{ Visits Not Receiving ACE/ARB } \\
\hline & & Frequency & $\%$ & Frequency & $\%$ \\
\hline \multirow[t]{4}{*}{ Age } & $<65$ & 496 & 34.56 & 1,038 & 65.44 \\
\hline & $65-74$ & 1,023 & 42.79 & 1,489 & 57.21 \\
\hline & $75-84$ & 689 & 42.06 & 1,107 & 57.94 \\
\hline & $85 \&$ above & 166 & 37.40 & 303 & 62.60 \\
\hline \multirow[t]{2}{*}{ Sex } & Female & 1,311 & 40.48 & 2,142 & 59.52 \\
\hline & Male & 1,063 & 40.95 & 1,795 & 59.05 \\
\hline \multirow[t]{4}{*}{ Race/Ethnicity } & Non-Hispanic White & 1536 & 40.13 & 2588 & 59.87 \\
\hline & Non-Hispanic Black & 501 & 40.05 & 742 & 59.95 \\
\hline & Hispanic & 230 & 44.87 & 401 & 55.13 \\
\hline & Other & 107 & 43.18 & 206 & 56.82 \\
\hline Private & No & 1,612 & 40.12 & 2,678 & 59.88 \\
\hline Insurance & Yes & 762 & 41.59 & 1,259 & 58.41 \\
\hline \multirow[t]{2}{*}{ Medicaid } & No & 2,034 & 40.84 & 3,249 & 59.16 \\
\hline & Yes & 340 & 39.52 & 688 & 60.48 \\
\hline \multirow[t]{2}{*}{ Bachelor's Degree or Higher in Patient's } & Quartile 1 & 694 & 40.37 & 1,166 & 59.63 \\
\hline & Quartile 2 & 600 & 42.13 & 977 & 57.87 \\
\hline \multirow[t]{2}{*}{ ZIP code } & Quartile 3 & 550 & 42.60 & 932 & 57.40 \\
\hline & Quartile 4 & 436 & 37.32 & 719 & 62.68 \\
\hline Median Household & Quartile 1 & 720 & 36.90 & 1,305 & 63.10 \\
\hline Income in Patient's & Quartile 2 & 599 & 46.13 & 973 & 53.87 \\
\hline \multirow[t]{2}{*}{ zip code } & Quartile 3 & 528 & 40.71 & 818 & 59.29 \\
\hline & Quartile 4 & 433 & 39.43 & 698 & 60.57 \\
\hline \multirow[t]{4}{*}{ Region } & Northeast & 667 & 39.49 & 1,007 & 60.51 \\
\hline & Midwest & 565 & 42.20 & 929 & 57.80 \\
\hline & South & 813 & 40.91 & 1,404 & 59.09 \\
\hline & West & 329 & 39.49 & 597 & 60.51 \\
\hline \multirow[t]{2}{*}{ MSA } & Non-MSA & 359 & 40.27 & 542 & 59.73 \\
\hline & MSA & 2,015 & 40.78 & 3,395 & 59.22 \\
\hline Primary Care ${ }^{a}$ & No & 1,241 & 32.56 & 2,679 & 67.44 \\
\hline Physician Visit & Yes & 1,045 & 48.39 & 1,109 & 51.61 \\
\hline \multirow[t]{4}{*}{ Number of Chronic Conditions } & 2 & 387 & 37.97 & 801 & 62.03 \\
\hline & 3 & 754 & 40.31 & 1,195 & 59.69 \\
\hline & 4 & 658 & 43.67 & 959 & 56.33 \\
\hline & 5 or more & 575 & 40.16 & 981 & 59.84 \\
\hline
\end{tabular}

J Pharm Health Serv Res. Author manuscript; available in PMC 2014 March 01. 
Table 3

Multivariate logistic regression for the association of patient characteristics with likelihood of receiving ACE/ ARB among visits made by Medicare beneficiaries with hypertension and Diabetes

\begin{tabular}{|c|c|c|c|c|c|c|c|}
\hline \multirow{2}{*}{$\begin{array}{l}\text { Parameter } \\
\text { Intercept }\end{array}$} & \multirow{2}{*}{$\begin{array}{r}\text { Estimate } \\
-1.47\end{array}$} & \multirow{2}{*}{$\begin{array}{r}\text { Standard Error } \\
0.37\end{array}$} & \multirow{2}{*}{$\begin{array}{r}\text { Wald Chi-Square } \\
15.83\end{array}$} & \multirow{2}{*}{$\begin{array}{r}\text { P-Value } \\
<0.01\end{array}$} & \multirow{2}{*}{$\begin{array}{r}\text { Odds Ratio } \\
-\end{array}$} & \multicolumn{2}{|c|}{$\begin{array}{l}\text { 95\% Confidence Interval } \\
\text { for Odds Ratio }\end{array}$} \\
\hline & & & & & & - & - \\
\hline Age & 0.01 & $<0.01$ & 3.70 & 0.05 & 1.01 & 1.00 & 1.01 \\
\hline Female & - & - & - & - & - & - & - \\
\hline Male & 0.02 & 0.08 & 0.05 & 0.82 & 1.02 & 0.86 & 1.20 \\
\hline Non-Hispanic White & - & - & - & - & - & - & - \\
\hline Non-Hispanic Black & 0.10 & 0.16 & 0.42 & 0.52 & 1.11 & 0.82 & 1.50 \\
\hline Hispanic & 0.15 & 0.14 & 1.11 & 0.29 & 1.16 & 0.88 & 1.53 \\
\hline Other & 0.19 & 0.27 & 0.50 & 0.48 & 1.21 & 0.71 & 2.05 \\
\hline No Private Insurance & - & - & - & - & - & - & - \\
\hline Private Insurance & 0.12 & 0.14 & 0.78 & 0.38 & 1.13 & 0.86 & 1.48 \\
\hline No Medicaid & - & - & - & - & - & - & - \\
\hline Medicaid & -0.05 & 0.14 & 0.13 & 0.71 & 0.95 & 0.72 & 1.25 \\
\hline Education Quartile 1 & - & - & - & - & - & - & - \\
\hline Education Quartile 2 & -0.02 & 0.13 & 0.03 & 0.86 & 0.98 & 0.75 & 1.26 \\
\hline Education Quartile 3 & -0.03 & 0.13 & 0.04 & 0.84 & 0.97 & 0.75 & 1.26 \\
\hline Education Quartile 4 & -0.21 & 0.19 & 1.19 & 0.28 & 0.81 & 0.56 & 1.18 \\
\hline Income Quartile 1 & - & - & - & - & - & - & - \\
\hline Income Quartile 2 & 0.37 & 0.13 & 8.31 & $<0.01$ & 1.45 & 1.13 & 1.87 \\
\hline Income Quartile 3 & 0.15 & 0.15 & 0.93 & 0.33 & 1.16 & 0.86 & 1.56 \\
\hline Income Quartile 4 & 0.20 & 0.21 & 0.89 & 0.34 & 1.22 & 0.81 & 1.84 \\
\hline Northeast & - & - & - & - & - & - & - \\
\hline Midwest & $<0.01$ & 0.22 & $<0.01$ & 0.96 & 1.00 & 0.65 & 1.55 \\
\hline South & 0.05 & 0.20 & 0.17 & 0.79 & 1.06 & 0.71 & 1.58 \\
\hline West & -0.11 & 0.27 & 0.16 & 0.69 & 0.90 & 0.53 & 1.52 \\
\hline Non-MSA & - & - & - & - & - & - & - \\
\hline MSA & 0.12 & 0.19 & 0.37 & 0.55 & 1.12 & 0.77 & 1.64 \\
\hline $\begin{array}{l}\text { Non-Primary Care Physician } \\
\text { Visit }\end{array}$ & - & - & - & - & - & - & - \\
\hline Primary Care Physician Visit & 0.67 & 0.11 & 38.68 & $<.0001$ & 1.96 & 1.59 & 2.43 \\
\hline $\begin{array}{l}\text { Number of Chronic } \\
\text { Conditions }\end{array}$ & -0.02 & 0.04 & 0.41 & 0.52 & 0.98 & 0.91 & 1.05 \\
\hline
\end{tabular}

Variables based on the Andersen's model: predisposing factors (age, sex and race/ethnicity), enabling factors (private insurance, Medicaid, education, income, region, metropolitan statistical area and primary care physician visit), and need factor (number of chronic conditions). 